\title{
Chemical analysis of refractory stratospheric aerosol particles collected within the arctic vortex and inside polar stratospheric clouds
}

\author{
Martin Ebert ${ }^{1}$, Ralf Weigel ${ }^{2}$, Konrad Kandler ${ }^{1}$, Gebhard Günther ${ }^{3}$, Sergej Molleker ${ }^{2}$, Jens-Uwe Grooß ${ }^{3}$, \\ Bärbel Vogel $^{3}$, Stephan Weinbruch ${ }^{1}$, and Stephan Borrmann ${ }^{2,4}$ \\ ${ }^{1}$ Institut für Angewandte Geowissenschaften, Technische Universität Darmstadt, Darmstadt, Germany \\ ${ }^{2}$ Institut für Physik der Atmosphäre, Johannes Gutenberg-Universität, Mainz, Germany \\ ${ }^{3}$ Institute for Energy and Climate Research (IEK-7), Research Center Jülich, Jülich, Germany \\ ${ }^{4}$ Partikelchemie, Max-Planck-Institut für Chemie, Mainz, Germany
}

Correspondence to: Martin Ebert (mebert@geo.tu-darmstadt.de)

Received: 10 February 2016 - Published in Atmos. Chem. Phys. Discuss.: 3 March 2016

Revised: 17 June 2016 - Accepted: 21 June 2016 - Published: 12 July 2016

\begin{abstract}
Stratospheric aerosol particles with diameters larger than about $10 \mathrm{~nm}$ were collected within the arctic vortex during two polar flight campaigns: RECONCILE in winter 2010 and ESSenCe in winter 2011. Impactors were installed on board the aircraft M-55 Geophysica, which was operated from Kiruna, Sweden. Flights were performed at a height of up to $21 \mathrm{~km}$ and some of the particle samples were taken within distinct polar stratospheric clouds (PSCs). The chemical composition, size and morphology of refractory particles were analyzed by scanning electron microscopy and energy-dispersive X-ray microanalysis. During ESSenCe no refractory particles with diameters above $500 \mathrm{~nm}$ were sampled. In total 116 small silicate, Fe-rich, Pb-rich and aluminum oxide spheres were found. In contrast to ESSenCe in early winter, during the late-winter RECONCILE mission the air masses were subsiding inside the Arctic winter vortex from the upper stratosphere and mesosphere, thus initializing a transport of refractory aerosol particles into the lower stratosphere. During RECONCILE, 759 refractory particles with diameters above $500 \mathrm{~nm}$ were found consisting of silicates, silicate / carbon mixtures, Fe-rich particles, Ca-rich particles and complex metal mixtures. In the size range below $500 \mathrm{~nm}$ the presence of soot was also proven. While the data base is still sparse, the general tendency of a lower abundance of refractory particles during PSC events compared to non-PSC situations was observed. The detection of large refractory particles in the stratosphere, as well as the
\end{abstract}

experimental finding that these particles were not observed in the particle samples (upper size limit $\sim 5 \mu \mathrm{m}$ ) taken during PSC events, strengthens the hypothesis that such particles are present in the lower polar stratosphere in late winter and have provided a surface for heterogeneous nucleation during PSC formation.

\section{Introduction}

Refractory (low-volatile) aerosol particles that are released into the atmosphere due to natural processes (e.g., desert dust storms, volcanism, pyrocumulus clouds and meteoric ablation) or stem from anthropogenic sources (e.g., space debris, aircraft/rocket exhaust and fossil fuel burning) are generally assumed to contribute significantly to stratospheric aerosol composition (Carslaw and Kärcher, 2006). The kind and strength of the impact of refractory particles of specific sources to the overall stratospheric aerosol load vary with altitude and latitude. The respective contribution of the refractory species depends on their fluxes into the stratosphere, which are to a large extent not yet quantifiable.

One major source region of stratospheric refractory particles is assumed to be the interplanetary space (Murphy et al., 1998, 2007a; Plane, 2012), where cosmic dust is incorporated into the Earth's atmosphere. Additionally, when larger cosmic bodies enter the upper atmosphere, a trace of ablation 
smoke is left behind (also referred to as meteoritic smoke particles, hereafter MSPs) due to high-temperature vaporization caused by the friction with air molecules. Estimates of the global influx of material from space are highly uncertain and vary within 2 orders of magnitude between $\sim 3$ and $300 \mathrm{tday}^{-1}$ (Plane, 2012). Apart from cosmic influx, aerosol particles from the troposphere which are lifted into the stratosphere due to effective vertical transport mechanisms (cf. Gettelman et al., 2011) also presumably contribute to the stratospheric aerosol composition. Some contribution to the stratospheric aerosol load may be provided by moderate tropical or subtropical volcanism (e.g., Soufrière Hills or Nabro) even though the volcano's vertical expulsion energy is too weak to directly inject material into the stratosphere, in contrast, for example, to the 1991 Pinatubo eruption. The ejected particulate matter accumulates in the upper troposphere (Mattis et al., 2010) or lower stratosphere (Vernier et al., 2011; Borrmann et al., 2010), where the BrewerDobson circulation likely lofts these particles to higher altitudes within the stratosphere (Vernier et al., 2011). Of course, aerosol material from other terrestrial sources (fine-mode desert dust or biomass burning material from boreal fires) could also follow this pathway into the stratosphere unless these species vanish due to in-cloud processes (solution in the liquid phase and chemical transformation) or precipitation (Fromm et al., 2000; Jost et al., 2004)

The present work focusses on analyses of particles sampled within or nearby the Arctic winter vortex. The transport pathways of material in the upper stratosphere and mesosphere converge towards the polar regions. The poleward transport at high atmospheric altitudes (i.e., in the upper stratosphere and mesosphere) is driven by the development of a polar vortex (Megner et al., 2008; Saunders et al., 2012; Bardeen et al., 2008; Hervig et al., 2009) occurring alternatingly twice per year, in the Arctic and the Antarctic. The vertical transport inside the vortices due to large-scale air mass subsidence provides a fast, and likely most effective, removal pathway of mesospheric and stratospheric material into the lowermost stratosphere and upper troposphere, which takes place over timescales of weeks to months during polar winter (Curtius et al., 2005; Weigel et al., 2014). Once the vortex dissolves in late polar spring, the included aerosol material is released towards lower latitudes within the lowermost stratosphere. Indications for this process are provided by MSPs identified in the midlatitude lowermost stratosphere by in situ laser ablation mass spectrometry (Murphy et al., 1998, 2013; Cziczo et al., 2001). Though these studies do not unambiguously link the transport history of observed MSPs to previous vortex subsidence, it is likely that these MSPs underwent the polar downward transport pathway prior to their effusion into the midlatitude lowermost stratosphere. Due to the vertical transport in connection with subsidence of mesospheric air over the Arctic winter, the contribution of MSPs is expected to dominate the in-vortex refractory aerosol composition. However, if tropospheric material is lofted from the tropics lower stratosphere by the Brewer-Dobson circulation into the upper stratosphere, a certain contribution of terrestrial material (e.g., silicates, soot) can be expected, but this needs to be proven.

In the Arctic mesosphere the abundance of refractory particles, presumably mostly dominated by MSPs, is demonstrated by detection of charged ultrafine particles $(<100 \mathrm{~nm}$ diameter) at concentrations of 40-1000 of positive or negative charges per cubic centimeters (Rapp et al., 2007; Rapp and Strelnikova, 2009). Rocket-borne detection of charged particles with concentrations of the order of thousands per $\mathrm{cm}^{3}$ at an altitude between 80 and $90 \mathrm{~km}$ (Amyx et al., 2008; Rapp et al., 2012; Friedrich et al., 2012; Plane et al., 2014) confirms the previous remote sensing studies. At lower altitudes in the Arctic vortex stratosphere, the abundance of non-volatile aerosol material was observed by means of airborne in situ investigations at up to $21 \mathrm{~km}$ (Curtius et al., 2005; Weigel et al., 2014), yielding about 100 particles per milligram of air, providing a fractional contribution of up to $75 \%$ to the total concentration of in-vortex particles. Further in situ observations at $24-27 \mathrm{~km}$ altitude also indicate in the Antarctic stratosphere (Campbell and Deshler, 2014) that there is a relative increase of refractory aerosol, contributing a fraction of up to $80 \%$ to total concentrations.

Refractory aerosol particles have particular importance in the stratosphere as they may generally provide surfaces for heterogeneous chemical reactions (e.g., chlorine activation). Furthermore, the presence of surfaces promotes the condensation of saturated gaseous compounds. It can be assumed that the presence of refractory aerosols such as MSPs or volcanic material impacts the maintenance of the stratospheric aerosol layer (Junge layer). Bigg (2012) even suggests that MSPs play a major role in controlling the stratospheric background aerosol. Whenever refractory particles in the atmosphere concur with saturated gaseous compounds (e.g., $\mathrm{H}_{2} \mathrm{SO}_{4}, \mathrm{HNO}_{3}$ or $\mathrm{H}_{2} \mathrm{O}$ ), the particles provide surfaces onto which vapors nucleate heterogeneously (cf. Saunders et al., 2010, 2012; Bigg, 2012; Frankland et al., 2015). Compounds of refractory aerosol may dissolve in acidic solutions which could impact the freezing properties of, for example, binary $\mathrm{HNO}_{3}-\mathrm{H}_{2} \mathrm{O}$ or ternary $\mathrm{HNO}_{3}-\mathrm{H}_{2} \mathrm{SO}_{4}-\mathrm{H}_{2} \mathrm{O}$ solution droplets. Thus, solutes of an refractory particle in a $\mathrm{HNO}_{3}-$ $\mathrm{H}_{2} \mathrm{SO}_{4}-\mathrm{H}_{2} \mathrm{O}$ droplet could have crucial impact on formation of polar stratospheric clouds (PSCs) (Chang et al., 1999; Wise et al., 2003). Due to condensation of vapors the refractory cores grow, which has direct implication for the particles mass and sedimentation speed, thereby promoting a redistribution or removal of the condensed material.

The number of terrestrial supermicron refractory aerosol particles in the middle atmosphere is low as micrometersized particles are removed quickly due to sedimentation. The model study of Dhomse et al. (2013) concerning atmospheric redistribution of ${ }^{238} \mathrm{PuO}_{2}$ particles revealed that submicron particles reside about 4 years in the atmosphere before reaching the surface. 
Some of the first scanning electron microscopy (SEM) images of aerosol particles that were sampled at altitudes of 20 $37 \mathrm{~km}$ were provided by Bigg et al. $(1970,1971)$. Presumably, meteoritic ablation particles are shown here as agglomerates of small spherical particles. Due to the gap of chemical analysis techniques at these times it can only be assumed that the collected spheroids were previously exposed to high (melting point) temperatures. Further SEM/EDX (energydispersive X-ray detector; EDAX, Tilburg, the Netherlands) analysis of particles sampled in the stratosphere was shown by Mackinnon et al. (1982). These authors were able to attribute large amounts of collected particles to their cosmic origin.

Knowledge of the physicochemical properties of refractory aerosol in the stratosphere is still sparse. Large uncertainties remain concerning the relative contribution of different sources such as meteoritic ablation material, terrestrial crustal particles or ablation of space debris. During two Arctic airborne missions with the Russian high-altitude research aircraft M-55 Geophysica, located in Kiruna, Sweden, particles samples were taken in the vortex stratosphere, exclusively above $410 \mathrm{~K}$ potential temperature. The major aim of the present study is to gain insight into the contribution of refractory particles of different origin to the overall stratospheric aerosol composition. Furthermore, several samples were collected when penetrating extended PSC fields. Thus, chemical analysis of these particles may help to better understand their role in PSC formation.

\section{Methods}

\subsection{Sampling campaigns}

Particles were collected during two polar stratospheric campaigns in arctic winters 2010 and 2011. Both campaigns were scheduled for flights within the polar vortex and carried out under potential PSC conditions. Flights were operated from Kiruna, Sweden, with the high-altitude aircraft M55-Geophysica. This research aircraft can reach a maximum altitude of $21 \mathrm{~km}$ and has a total range of about $2500 \mathrm{~km}$ (Stefanutti et al., 1999). The RECONCILE (Reconciliation of essential process parameters for an enhanced predictability of Arctic stratospheric ozone loss and its climate interactions) campaign (von Hobe et al., 2013) in arctic winter 2010 (January-March) focused on central questions regarding polar ozone depletion: among others, the role of cold binary aerosols in heterogeneous chlorine activation and polar stratospheric cloud processes including heterogeneous nucleation of nitric acid trihydrate (NAT) and ice on non-volatile background aerosol. The suite of instruments merged within Geophysica during the RECONCILE campaign was the most comprehensive one to date with respect to PSC processes flown on a single aircraft (von Hobe et al., 2013). While the main objective of the ESSenCe (ESA Sounder Cam- paign) campaign in December 2011 was the in-flight testing of the GLORIA (Gimballed Limb Observer for Radiance Imaging of the Atmosphere) instrument and thereby the retrieval of three-dimensional small-scale structures in uppertropospheric/lower-stratospheric composition (Kaufmann et al., 2015), ESSenCe provided a second opportunity to collect stratospheric aerosol under partly comparable conditions to RECONCILE.

\subsection{Sampling technique}

All aerosol samples during the RECONCILE campaign were taken from the inlet line of COPAS (COndensation PArticle counting System; Curtius et al., 2005; Weigel et al., 2009; Borrmann et al., 2010) with a Y-shaped manifold.

According to Weigel et al. (2009) the inlet efficiency can be compared with the similarly designed and operated inlet system presented by Hermann et al. (2001). For submicron particles, the transmission efficiency of the COPAS aerosol inlet is $90 \%$ or higher. The inlet performance rapidly deteriorates for particles of micrometer size (about 30-40\% for particles with $4 \mu \mathrm{m}$ diameter). The transmission efficiency of the COPAS inlet for particles with diameter larger than about $6 \mu \mathrm{m}$ is below $5 \%$.

Particle collection was performed with a dual-stage cascade impaction system (MINI; Micro Inertial Impactor, Kandler et al., 2007) with orifices of 0.75 and $0.25 \mathrm{~mm}$ and a jet-to-plate distance of 1.5 times the orifice diameter (Fig. 1 left). Air velocity in the second nozzle is at speed of sound and, thus, controlling the impactor flow, which was calculated to be $7.7 \mathrm{~cm}^{3} \mathrm{~s}^{-1}$ at stratospheric conditions. Temperature in the COPAS system varied between 272 and $290 \mathrm{~K}$ and pressure between 50 and $67 \mathrm{hPa}$. Efficiency cutoffs of $50 \%$ for these values calculated according to Raabe et al. (1988) are $400 \mathrm{~nm}$ aerodynamic diameter for the first impactor stage and smaller than $10 \mathrm{~nm}$ for the second. In the present paper, particles in the first impactor stage are referred to as coarse fraction $(>400 \mathrm{~nm})$, while those in the second stage are fine fraction $(10-400 \mathrm{~nm})$. Note that under stratospheric conditions the strictness of the impactor size discrimination is expected to be lower than under tropospheric ones.

During ESSenCe, a newly constructed cascade impaction system (Multi-MINI) was used (Fig. 1 right). While the basic impaction geometry remains unchanged compared to the MINI, 12 dual-stage impactor units were integrated into a single housing. Particle sampling of the single units is controlled by a set of valves. A 12-fold symmetrical manifold delivers the aerosol to the separate units. In addition, a purge flow system was added to the Multi-MINI. The purge flow system fills the tubing and the interior of the manifold prior to sampling with the current outside aerosol to avoid any carryover of particles from previous measurements. The purge flow extends to the front of the first impaction nozzle, so the potential volume affected by carryover is minimal. The purge time $(7 \mathrm{~min})$ was chosen so that the tube and mani- 


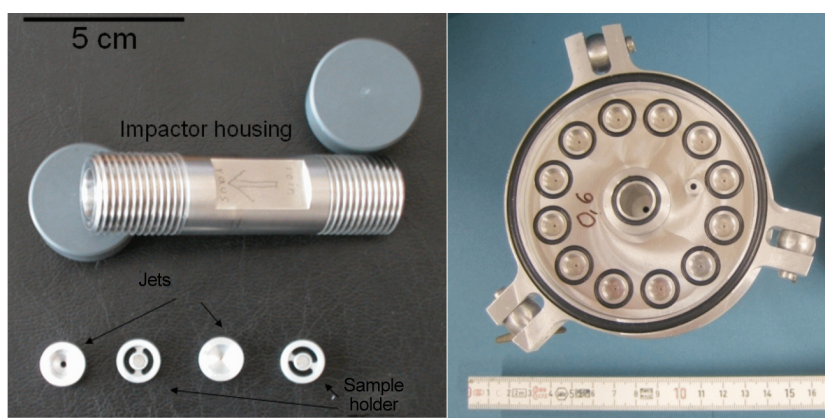

Figure 1. Left: single two-stage impactor used during RECONCILE. Right: multi-impactor system (allows 12 samples per flight) with purging system used during ESSenCe.

Table 1. Aerosol samples with corresponding flight date, potential temperature $(\mathrm{K})$ and the vortex indicator based on dynamic tracer measurements and CTM modeling for RECONCILE and ESSenCe (data from Weigel et al., 2014).

\begin{tabular}{llrrl}
\hline $\begin{array}{l}\text { Aerosol } \\
\text { sample }\end{array}$ & $\begin{array}{l}\text { Flight } \\
\text { date }\end{array}$ & $\begin{array}{r}\text { Potential } \\
\text { temperature } \\
(\mathrm{K})\end{array}$ & $\begin{array}{r}\text { Vortex } \\
\text { index }\end{array}$ & $\begin{array}{l}\text { Flight } \\
\text { campaign }\end{array}$ \\
\hline 1 & 17 Jan 2010 & $410-425$ & 0.6 & $\mathrm{R}$ \\
2 & 20 Jan 2010 & $410-420$ & 0.2 & $\mathrm{E}$ \\
3 & 22 Jan 2010 & $415-430$ & 0.9 & $\mathrm{C}$ \\
4 & 24 Jan 2010 & $425-430$ & 0.3 & $\mathrm{O}$ \\
5 & 25 Jan 2010 & $440-450$ & 0.9 & $\mathrm{~N}$ \\
6 & 28 Jan 2010 & $440-450$ & 0.2 & $\mathrm{C}$ \\
8 & 2 Feb 2010 & $425-445$ & - & $\mathrm{I}$ \\
9 & 27 Feb 2010 & $480-515$ & 0.9 & $\mathrm{~L}$ \\
10 & 2 Mar 2010 & $460-470$ & 1.0 & \\
12 & 5 Mar 2010 & $480-490$ & 0.9 & $\mathrm{E}$ \\
13 & 10 Mar 2010 & $480-490$ & 0.8 & \\
\hline $\mathrm{A}-\mathrm{F}$ & 16 Dec 2011 & $400-440$ & $0.7-1$ & $\mathrm{ESSenCe}$ \\
\hline
\end{tabular}

fold volume could be filled at least 10 times with the current aerosol. During RECONCILE and ESSenCe, the separate impactors were operated in the stratosphere for $20 \mathrm{~min}$ each. Particles were collected on self-constructed highly polished boron substrates (Choël et al., 2005), which are well suited for particle analysis by SEM and X-ray microanalysis. During RECONCILE, in the time period from 17 January to 10 March 2010, 11 samples were collected during 11 mission flights (Table 1). Twelve samples were collected during the only successful flight of the ESSenCe campaign on 16 December 2011.

An overview of the stratospheric conditions during sampling is given in Fig. 2. The main goal of the present study was the identification and characterization of refractory (nonvolatile) particles. As these particles are supposed to be extremely rare in the stratosphere, long sampling times of 20 min were chosen, leading to overloading of the substrates with the more abundant typical Junge layer aerosol (mainly

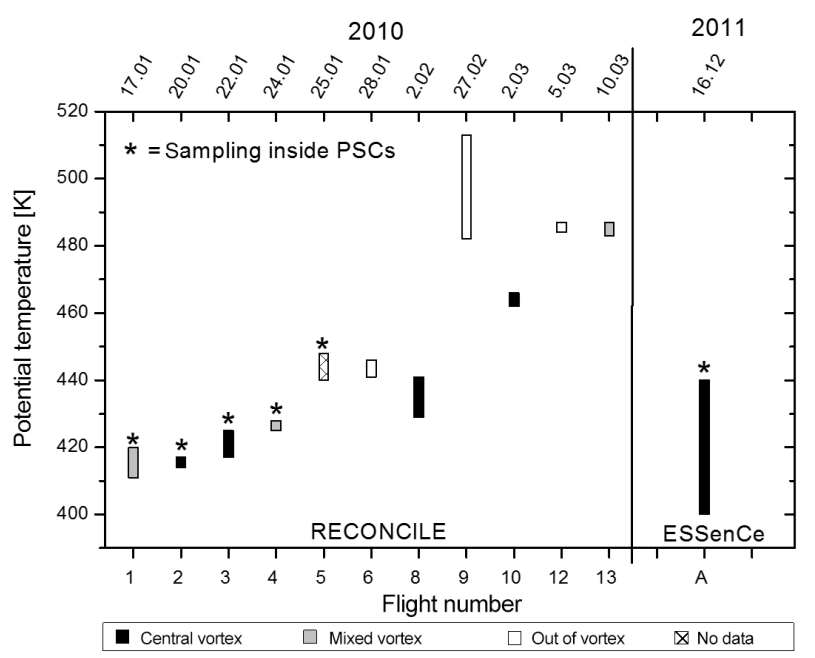

Figure 2. Potential temperature range, vortex situation and presence of polar stratospheric clouds for the 11 aerosol samples for RECONCILE (2010) and the ESSenCe sample (2011).

of volatile sulfuric compounds and nitrates). Therefore, the refractory particles are generally embedded in a matrix of sulfate / nitrate material, above all in the fine stage.

\subsection{Sample analysis by electron microscopy}

Individual particle analysis was performed in a FEI (Eindhoven, the Netherlands) Quanta 200 FEG Environmental Scanning Electron Microscope (ESEM) equipped with an EDX.

As a detailed analysis of the sulfates and nitrates was not intended, the presumable refractory particles were selectively analyzed using backscattered electron (BSE) images. The use of a boron substrate provides a high contrast between the substrate $(Z=5)$, the low- $Z$ ( $Z=7$ to 10$)$ and high- $Z(Z>10)$ particles in the BSE image. All particles with an average atomic number higher than for the Junge layer $(Z<10)$ can easily be identified as they appear brighter (white spots within the Junge layer particles). The elemental composition and morphology of all 759 detected high- $Z$ particles larger than $500 \mathrm{~nm}$ projected area diameter (from 11 RECONCILE flights) were studied in detail.

In contrast to the dominating sulfates and/or nitrates in the Junge layer, the high- $Z$ particles are non-volatile under electron bombardment and the high vacuum conditions in the ESEM. In the following, the term "refractory" is used for these particles. Low $Z$ refractory particles (e.g., soot) with diameters above $500 \mathrm{~nm}$ were not observed on the coarse fraction stage. It must be noted, however, that some of the refractory particles were stable under a short electron bombardment only but showed slight signs of beam damage after considerably longer exposure times (e.g., the Ca-rich particles). The overloading of the fine fraction stage with sulfates and nitrates prevented a systematic quantitative analysis of 


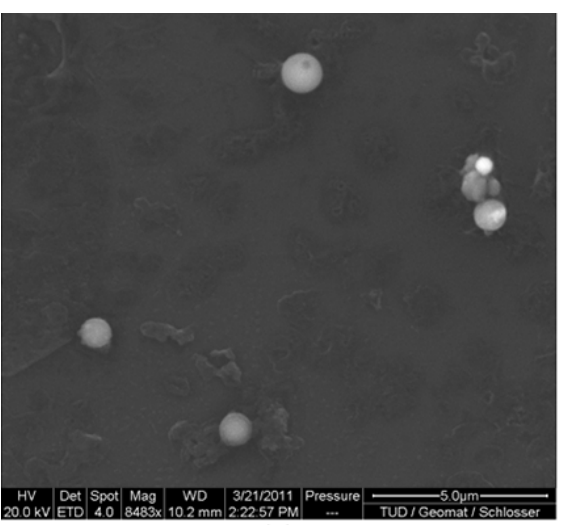

(a)

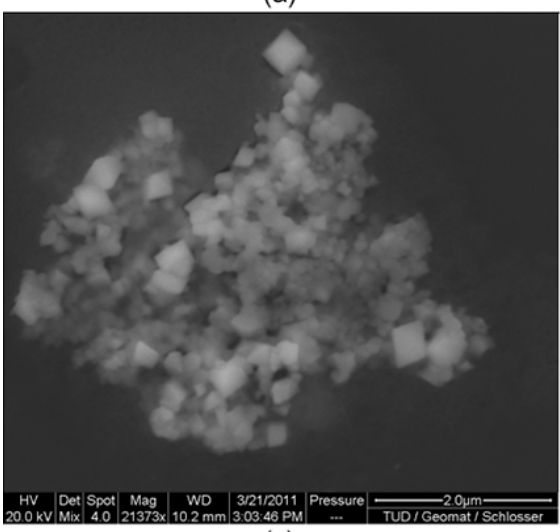

(c)

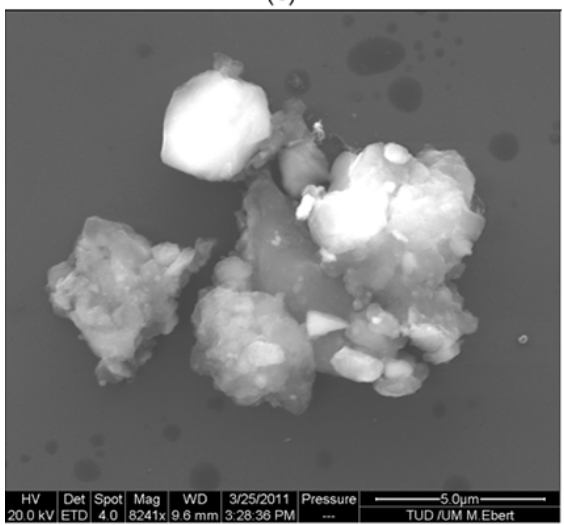

(e)

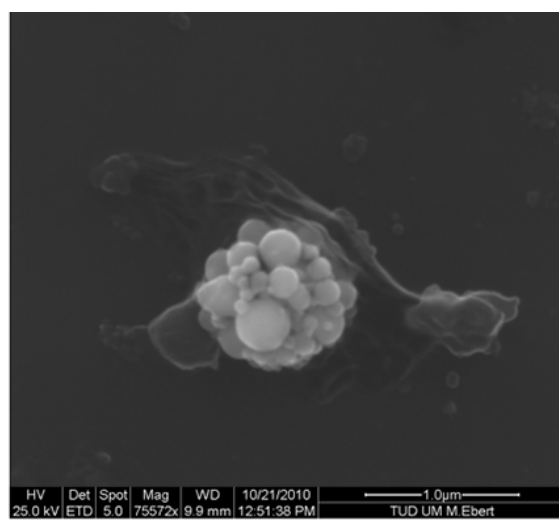

(b)

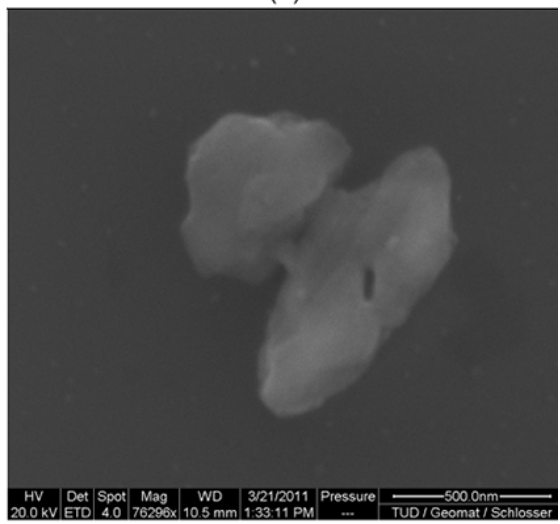

(d)

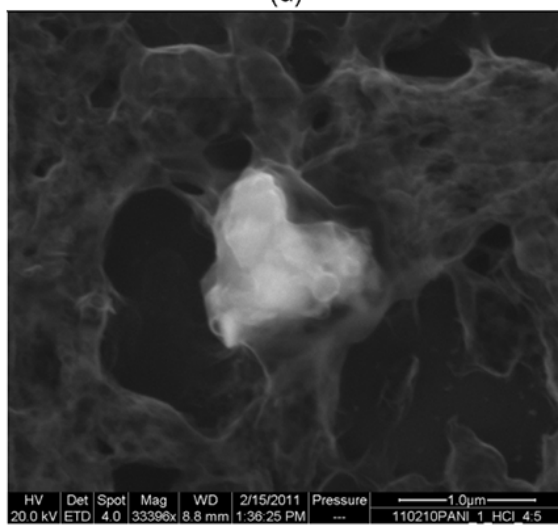

(f)

Figure 3. Secondary electron images of refractory particles in the coarse fraction: (a) silicatic spheres; (b) Fe-rich particle; (c) complex metallic mixture (Al / Cr / Mn / Fe); (d) Ca-rich particle; (e) carbon / silicate mixture; (f) silicate particle.

smaller refractory particles. Thus, the abundance ratio of refractory to non-refractory particles could not be determined quantitatively for this size-range. Nevertheless, the fine stage was analyzed for refractory material in order to obtain at least a qualitative estimate of the composition.

\section{Results}

\subsection{Volatile matrix}

Refractory particles, which are the focus of the present study, are only a small fraction of the total collected stratospheric aerosol particles. In all samples, the volatile Junge aerosol particles are the dominant particle group (visible in Fig. 5 and 7). These volatile particles are mainly composed of ammonium and sodium sulfates (Junge, 1963), which was also confirmed by the present study. These particles, however, are 


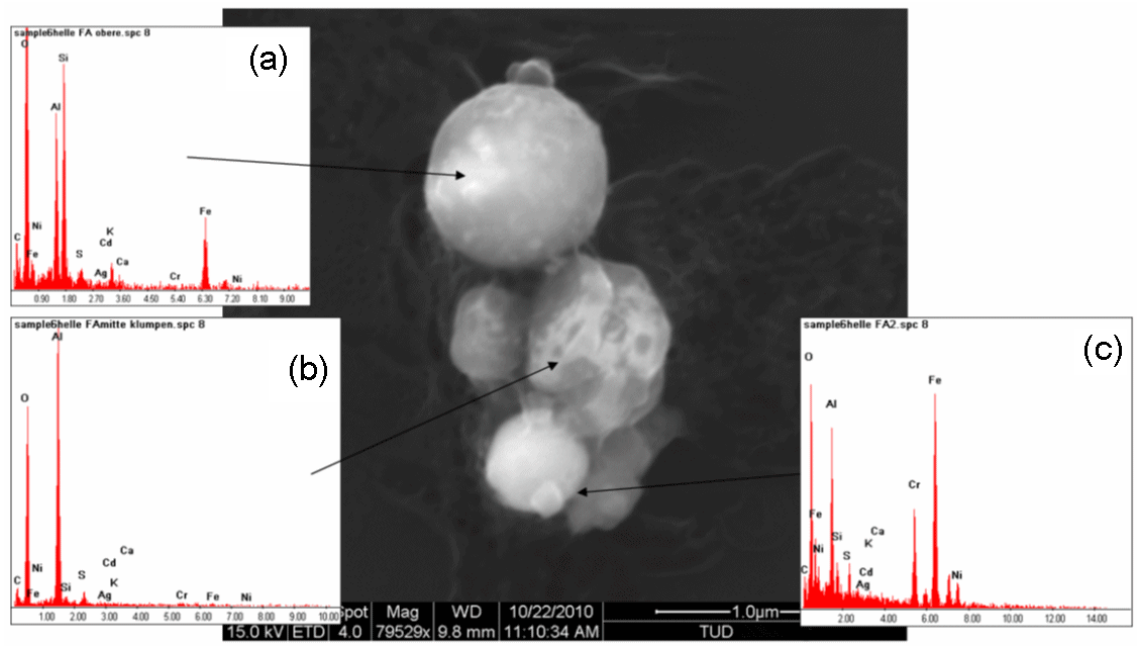

Figure 4. Secondary electron images of an agglomerate found during RECONCILE, containing (a) silicate sphere, (b) aluminium oxide particle and (c) complex metal mixture.

not considered within the scope of this work and are not regarded further.

\subsection{Refractory particles}

Based on morphology, chemistry and beam stability the following eight refractory particle groups were distinguished: Ca-rich particles, Fe-rich particles, silicates, C / Si mixed particles, mixed metal / metal oxides, Pb-rich particles, aluminum oxide spheres and soot.

All particles, with $\mathrm{Ca}$ as the main peak in the EDX spectrum, were classified as Ca-rich. A typical secondary electron image is given in Fig. 3d. In most of these particles no elements besides calcium, carbon, nitrogen and oxygen are detectable. Under electron bombardment, some of the particles show slight beam damage (visible in the center of the particle, Fig. 3d). The exact chemical compound (e.g., $\mathrm{CaCO}_{3}$, $\left.\mathrm{Ca}\left(\mathrm{NO}_{3}\right)_{2}, \mathrm{Ca}(\mathrm{OH})_{2}\right)$ cannot be determined by EDX. In total, 96 Ca-rich particles larger than $500 \mathrm{~nm}$ (13\% of all analyzed large refractory particles) were detected with highly varying abundance in 8 of the 11 RECONCILE samples. In 6 samples (nos. 1, 3, 8, 10, 13) only a low abundance of 1-14\% (equivalent to 1-8 particles sample ${ }^{-1}$ ) was observed, while in two samples ( 2 and 5 ) almost $70 \%$ of all detected large refractory particles were $\mathrm{Ca}$-rich. The high relative abundance in samples 2 and 5 also results from a higher absolute abundance (50 and $24 \mathrm{Ca}$-rich particles, respectively) and a lower abundance of other refractory particle types in these samples.

Particles with iron and oxygen as major X-ray peaks were classified as Fe-rich. A secondary electron image of a typical iron-rich particle is shown in Fig. 3b. More than $50 \%$ of these particles are single spheres or agglomerates of spheres, tellingly described by Bigg et al. (1970) as reminiscent of "a bunch of grapes", indicating an origin by high-temperature processes. In total 148 particles (20\%) of all detected large refractory particles were classified as iron-rich.

Particles with silicon and oxygen as major elements were classified as silicates. Approximately $80 \%$ of silicate particles are spheres or agglomerates of spheres (Fig. 3a), while the rest shows irregular shapes (Fig. 3f). In total 243 particles (32\%) of all detected large refractory particles were classified as silicates. They were found in all 11 samples with an abundance between 13 and $55 \%$ (6-45 particles sample $\left.{ }^{-1}\right)$.

Si-rich particles with additional high-carbon contents were classified in a C / Si-mixed group. These particles are often agglomerates of smaller irregular and/or spherical particles. In total 44 of all detected large refractory particles were classified as C / Si-mixed particles $(\sim 6 \%)$. This particle type was only observed in 6 of the 11 RECONCILE samples.

Mixed metal/metal oxide particles are rich in the elements $\mathrm{Fe}, \mathrm{Al}, \mathrm{Cr}, \mathrm{Mn}, \mathrm{Ni}$ and/or $\mathrm{Zn}$. Most particles of this group are dominated by $\mathrm{Fe}$ and $\mathrm{Al}$ but often with variable abundance of the other metals. All agglomerates that contain these metals are classified into this mixed group, even, for example, when silicates were attached to the agglomerates. Within agglomerates of this group, Fe-rich particles, Al-rich particles, silicates, alloy-like particles (Cr, Mn, Fe, Ni, Zn) and internal mixtures of all these components are found. The morphology of these particles is highly variable (Fig. 3c). These particles have a composition which shows similarities to certain anthropogenic metal alloys (steel). Around $75 \%$ of the mixed particles are spheres, contain spheres or show at least rounded structures (Fig. 4), which indicates a hightemperature origin. In 30 of the mixed particles, $\mathrm{K}$ and $\mathrm{F}$ were detected. Of all detected large refractory particles during RECONCILE, 228 were classified as mixed metal/metal oxide particles $(30 \%)$. The mixed metal / metal oxide particles were a major component in 7 of 11 RECONCILE sam- 


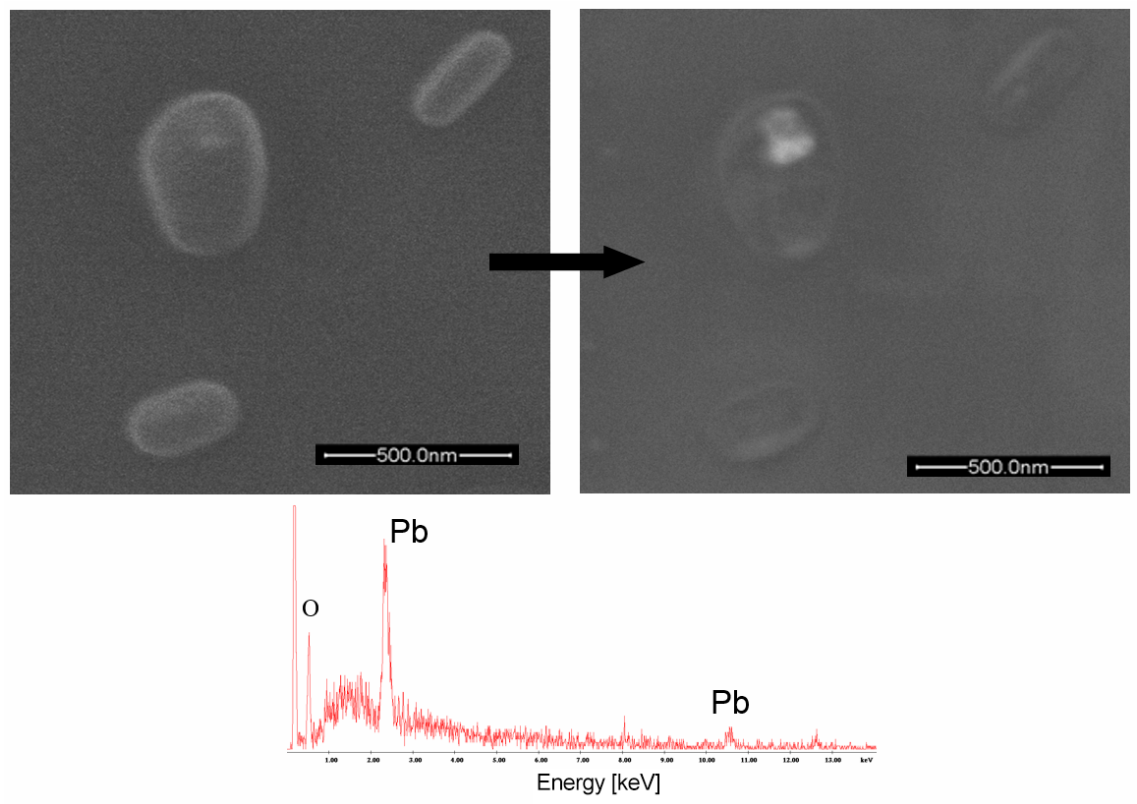

Figure 5. Left: three secondary particles containing different amounts of sulfates/nitrates/organics at the beginning of electron microscopic investigation. Right: under electron bombardment the material evaporates after a few seconds exhibiting a lead-rich inclusion.

ples (17-62\%) but completely absent in the 4 other samples $(2,4,5,9)$.

All 759 analyzed refractory particles larger than $500 \mathrm{~nm}$ belong to the five particle types presented so far. These five particle types were also found in the fine stage (particle diameters smaller than $500 \mathrm{~nm}$ ), together with three further refractory particle types, which were not found in the coarse stage.

A small number of $\mathrm{Pb}$-rich inclusions within volatile particles from the Junge layer aerosol (Figs. 5 and 6) were observed in the RECONCILE and ESSenCe samples. Due to their small size (often around $50 \mathrm{~nm}$ ) and the fact that these particles are often embedded in the secondary matrix, the chemical composition cannot be determined in more detail by SEM/EDX analysis.

Varying amounts of soot particles were observed in all RECONCILE samples (but not during ESSenCe). Soot can clearly be identified by its characteristic morphology as agglomerates of spherical primary particles. Most observed soot particles were internally mixed with sulfates (Fig. 6d) and become visible during the evaporation of volatile material under electron bombardment.

Additionally, some aluminum oxide spheres (AOSs) were detected in the fine stages of the ESSenCe campaign.

\subsection{Abundance during RECONCILE}

The particle group relative number abundance (PGNA) determined for the 11 flights is given in Fig. 8 .

The PGNA is highly variable for the different particle groups without any clear visible time trend. However, the fol- lowing patterns are obvious: samples $2,4,5$ and 9 show no mixed metal / metal oxide particles in contrast to all other samples. While samples 2 and 5 are dominated by Ca-rich particles with a relative number abundance of approximately $70 \%$, samples 4 and 9 are dominated by silicates plus C / Si mixed particles. Samples 3, 6, 8 and 10 have high relative number abundances of mixed metal / metal oxide particles (> $40 \%)$. The other samples $(1,12,13)$ have comparable high relative abundances of several particle groups. In addition, the relative number abundance of $\mathrm{C} / \mathrm{Si}$ mixed particles is always low $(0-20 \%)$.

When the PSC samples (1-5) are compared to non-PSC samples it becomes obvious that the former have (on average) a clearly higher abundance of Ca-rich particles and a lower abundance of Fe-rich and mixed metal / metal oxide particles. This is not true for each individual PSC flight, but it has to be assumed that even if samples 1-5 were sampled within a PSC (depending on the specific conditions during the 20 min sampling time), a varying amount of the deposited particles will be derived from "out of PSC" air masses.

The average diameter of the 759 detected refractory particles is $1.0 \mu \mathrm{m}$. A size distribution for all detected particle groups for the four particle diameter intervals $0.5-1,1-2,2$ 3 and $>3 \mu \mathrm{m}$ (equivalent projected area diameter) is given in Fig. 9. In Sect. 4 the calculated mass mixing ratio for the refractory particles will also be discussed. As expected, all particle groups show strongly decreasing particle numbers with increasing particle diameters; only the mixed metal / metal oxide groups show highest values for the size interval 1$2 \mu \mathrm{m}$, which will be discussed in Sect. 4.1.5. 


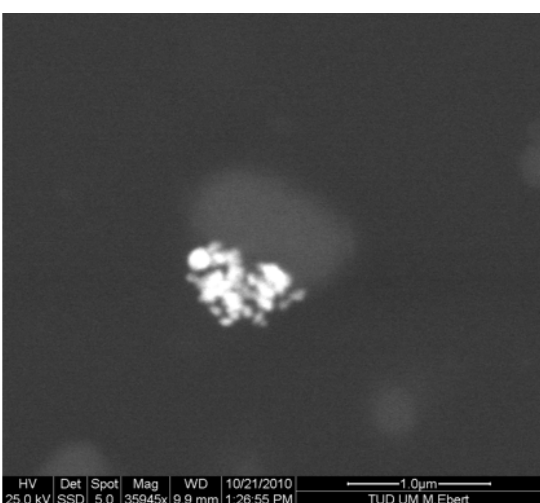

(a)

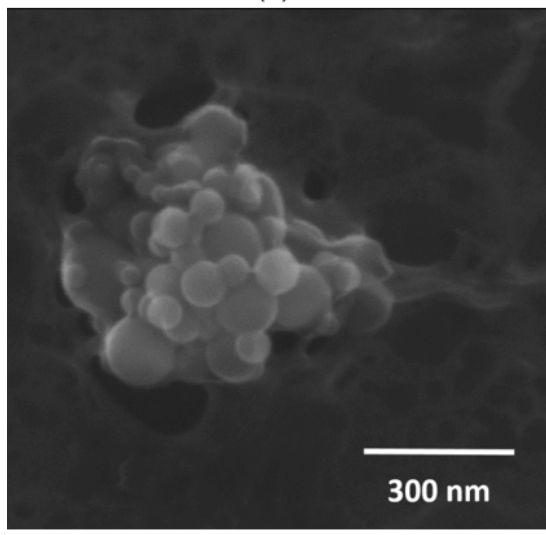

(c)

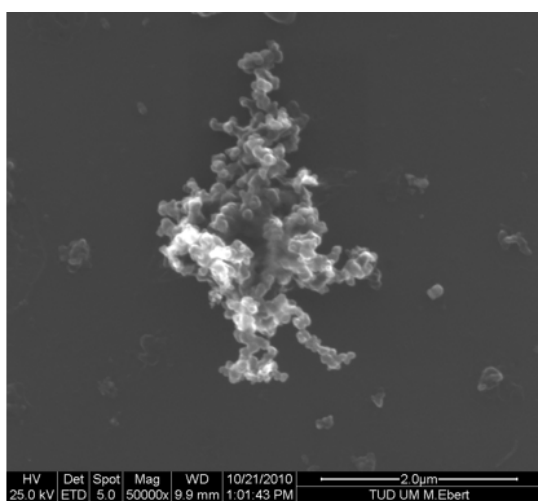

(b)

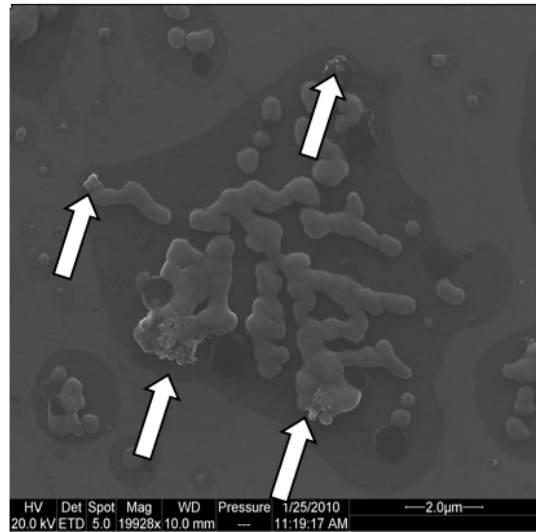

(d)

Figure 6. Secondary electron images of refractory particles in the fine fraction: (a) lead-rich agglomerate (bright) within a secondary particle; (b) soot particle; (c) agglomerate of spherical silicate particles; (d) soot inclusions (marked by arrows) within volatile material.

A systematic quantitative analysis of the refractory particles smaller than $500 \mathrm{~nm}$ on a flight-by-flight basis was not possible, because the fine fraction stage was overloaded with volatile particles, preventing analysis of individual particles. Nevertheless, some general findings can be reported. All refractory particle types for a certain flight, which were found in the coarse fraction, were also found in the fine fraction. Additionally, soot and $\mathrm{Pb}$-rich particles were observed in the fine fraction. The $\mathrm{Pb}$-rich particles are rare in general but seem to be present ubiquitously. In contrast, the soot abundance seems to be linked with the abundance of the mixed metal / metal oxide group. The samples without these particles show no soot at all or only few soot particles $(<10)$, while all samples with mixed metal / metal oxide particles show a considerable soot abundance. The samples with highest mixed metal / metal oxide abundance (flights 6, 8 and 10) also show the highest soot abundance.

\subsection{Abundance during ESSenCe}

Within the single flight of 16 December during the ESSenCe campaign, which was conducted in early winter (young vortex) within a PSC, no refractory particles larger than $500 \mathrm{~nm}$ were observed. Consequently, only the observations regard- ing the fine-fraction refractory particles can be reported here. Due to the low numbers of observed refractory particles and the inherent statistical uncertainty, all samples received during this flight were merged. In total, 116 refractory particles were detected and analyzed for the fine stages of all ESSenCe samples: 41 spherical silicates, 30 AOSs, 27 spherical Fe-rich particles and $18 \mathrm{~Pb}$-rich particles. Ca-rich particles, mixed metal / metal oxide particles, C / Si-mixed particles and soot, which were observed during RECONCILE, were not detected within the ESSenCe samples.

\section{Discussion}

In Fig. 9 the total number of detected refractory particles for the size ranges $0.5-1,1-2,2-3$ and larger than $3 \mu \mathrm{m}$ is shown. In principle, the number of detected particles can be used to assume an average number and mass concentration of the refractory particles during RECONCILE. As a variety of assumptions has to be made, the uncertainty for the received mass and number concentrations is large. For particles smaller than $500 \mathrm{~nm}$ no stratospheric concentration can be received on the basis of the electron microscopic samples because the large amount of volatile material prevents 


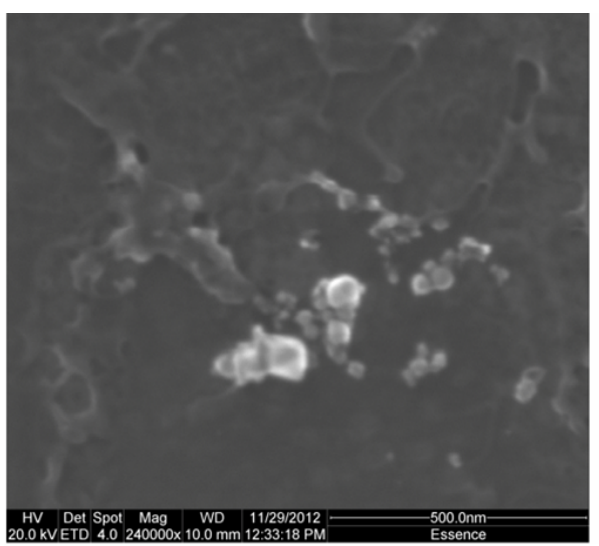

(a)

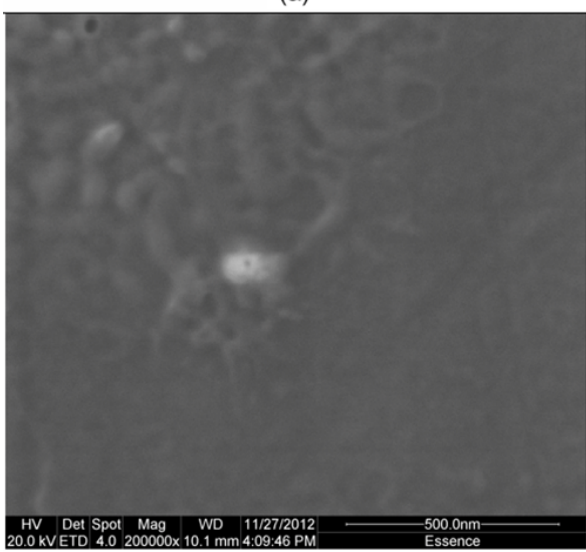

(c)

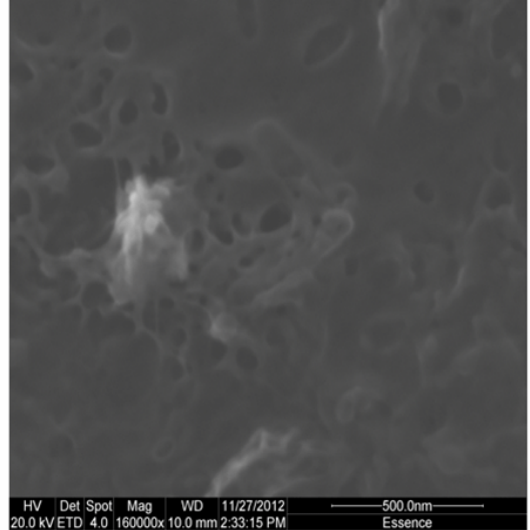

(b)

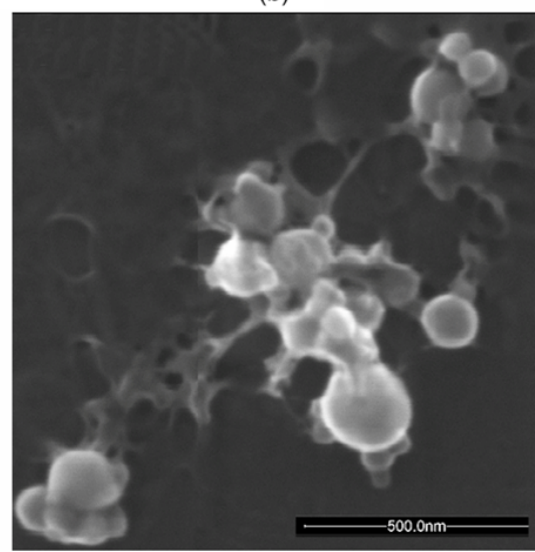

(d)

Figure 7. Secondary electron images of refractory particles in the fine fraction of ESSenCe samples: (a) aluminum oxide spheres; (b) Fe-rich particles; (c) Pb-rich particles; (d) Mg-rich silicates.

the determination of the total number of refractory particles in this stage. Considering the total sampled air volume, the average mass mixing ratio of the refractory particles (larger than $500 \mathrm{~nm}$ ) during RECONCILE will be in the range of $0.1 \mathrm{ppbm}$. The $\mathrm{d} N / \operatorname{dog} D_{\mathrm{P}}$ value for particle diameters of $0.75 \mu \mathrm{m}$ is around $10^{-2} \mathrm{~cm}^{-3}$. This number / mass loading can be compared with other studies under non-volcanic conditions in the stratosphere. Deshler et al. (2003) published the results of 30 years of in situ stratospheric aerosol size distribution measurements from Wyoming using balloon-borne instruments. They found an average mass mixing ratio for the large mode of $0.02,5$ times lower than the values determined in this study in late polar winter. Wilson et al. (2008) report an average mass mixing ratio of 0.4 to $0.8 \mathrm{ppbm}$ for the aerosol sulfate for the non-volcanic influenced time period 1999-2004 and for measurements in the polar vortex only a very low volume (close to 0 / linear ordinate) of particles larger than $500 \mathrm{~nm}$. Deshler (2008) reports in his review of global stratospheric aerosol measurements observations of local stratospheric aerosol layers. He mentioned that in the polar regions NAT forms readily on a small fraction $\left(10^{-4}-10^{-5}\right)$ of stratospheric aerosol particles through het- erogeneous nucleation. Following this value the fraction of nonvolatile stratospheric particles, which can act as heterogeneous nuclei, is at least 100 times lower as the total number of refractory particles, which we have observed during RECONCILE. He also reports balloon-borne measurements above the tropopause in Australia, where aerosol layers with particle diameters above $1 \mu \mathrm{m}$ and number concentrations as high as $10^{-2} \mathrm{~cm}^{-3}$ were observed. Size and number distribution of this layer seems comparable to our findings, although the possible sources are completely different (most probably thunderstorms) to our study. In Weigel et al. (2014) a variety of different model size distributions of stratospheric aerosol are shown. It can be seen that the high number of large particles $(>500 \mathrm{~nm})$ is on the upper limit of most model distributions. However, for such a comparison it must be taken into account that all presented size distributions do not refer in particular to the situation in the late polar winter vortex. In this way there is the need for further measurements of the stratospheric aerosol characteristics in late polar winter to confirm the observed findings.

During RECONCILE Weigel et al. (2014) had observed that the Arctic vortex in winter 2009/2010 showed an un- 


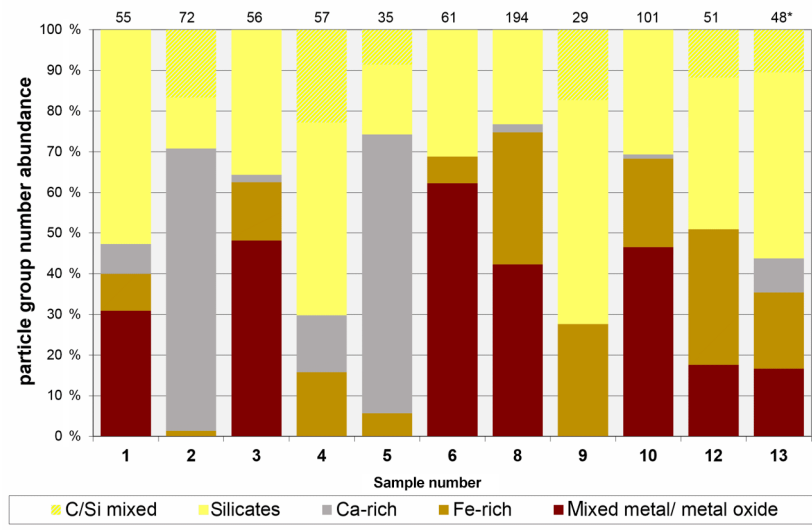

Figure 8. Particle group number abundance (PGNA) within 11 samples collected during RECONCILE flights. PGNA refers to refractory particles larger than $500 \mathrm{~nm}\left({ }^{*}\right.$ the number of analyzed particles is shown above each column).

usually strong subsidence. They found up to 11 submicron particles per $\mathrm{cm}^{3}$ and 8 of these 11 particles were found to contain thermo-stable $\left(250^{\circ} \mathrm{C}\right)$ residuals with diameters of $10 \mathrm{~nm}$ to $1 \mu \mathrm{m}$. Particle mixing ratios (up to 150 of nonvolatile particles per milligram air) and fractions of nonvolatile particles (up to $75 \%$ of totally detected particles) exhibited the highest values in air masses with the lowest content of nitrous oxide $\left(70 \mathrm{nmol} \mathrm{mol}^{-1} \mathrm{~N}_{2} \mathrm{O}\right)$. This indicates that refractory aerosol originates from the upper stratosphere or the mesosphere. They concluded that the impact of refractory aerosol material in the Arctic polar winter is a regular feature. Weigel et al. also estimate the total mass of mesospheric particles deposited over the 2009/2010 winter in the entire Arctic vortex to range between $77 \times 10^{3}$ and $375 \times 10^{6} \mathrm{~kg}$. This estimate yields an enhancement of the refractory aerosol mass by a factor of 4.5 at the lowermost vortex $(100-67 \mathrm{hPa})$ toward the end of an Arctic winter. He also compares this value with the expected influx of meteoric material $\left(110 \pm 55 \times 10^{3} \mathrm{~kg} \mathrm{day}^{-1}\right)$ and discusses the meaning of non-meteoric sources to the vortex refractory aerosol composition.

In the following subchapters we will present the different refractory particle groups that were detected during the RECONCILE and ESSenCe campaigns by our electron microscopic investigations. For each particle group a discussion about the possible origin and the specific contamination potential is included.

\subsection{Origin of the observed particle types}

\subsubsection{Ca-rich particles}

Ca-rich particles in the upper stratosphere were recently described by Della Corte et al. (2013). These authors specify $\mathrm{Ca}-\mathrm{C}-\mathrm{F}$ particles, calcite / aragonite particles and a porous aggregate of $\mathrm{Ca}(\mathrm{O})$ nanograins, sampled at $38 \mathrm{~km}$ height.

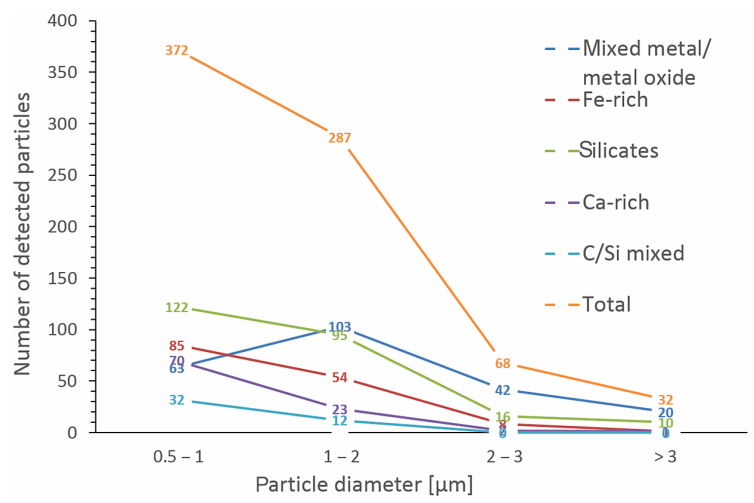

Figure 9. Size distribution of refractory particles during RECONCILE (coarse stage).

They also discovered a beam damage of these particles under SEM analysis, which was also observed in this study. They hypothesize meteoric dust smoke as source for these particles. While this cannot be proven based on the available data, Ca-rich particles are at a low risk to be an instrumental artifact, as Della Corte et al. (2013) used a totally different sampling setup.

\subsubsection{Fe-rich particles}

In many airborne upper troposphere/lower stratosphere measurements, "iron-rich/metallic" particles were reported (e.g., Targino et al., 2006). However, most studies give no further details about these particles, not even which actual metals were detected. Zolensky et al. (1989) found two different Fe-rich particle types, one with high contents of sulfur and one type without sulfur. In the present study, this differentiation is not possible because of the sample overloading and the subsequent strong agglomeration of the sulfurcontaining volatile material with most of the refractory particles (e.g., visible in Fig. 3b and f). Xu et al. (2001) also applied SEM/EDX for the characterization of individual stratospheric particles. They detected no particles larger than $500 \mathrm{~nm}$ particle diameter but, in the size range $100-500 \mathrm{~nm}$, iron-rich particles were the main component of the refractory particles. Mossop (1965) had already suggested in 1965 that small Fe-containing particles may be of extraterrestrial origin. For example, Hua and Buseck (1998) report on $\mathrm{Fe}_{3} \mathrm{O}_{4}$ spherules observed in carbonaceous chondrites. Another possible source for these particles is anthropogenic space debris or MDP (Zolensky et al., 1989).

Iron and iron oxide have some risk to be instrumental artifacts, as these particles could be produced by abrasion of iron-containing material, which is used for aircraft and inlet design. For example, Murphy et al. (2004) describe this effect. However, abrasion particles show in principle no spherical morphology. Furthermore, they show often other alloy components such as $\mathrm{Cr}, \mathrm{Mn}$ or $\mathrm{Ni}$, usually derived from stain- 
less steel components. As consequence, we do not regard the Fe-rich particles as artifacts.

\subsubsection{Silicates}

In stratospheric samples silicates are often described as the main refractory component. Most often chondritic material from cosmic dust is discussed as the source for these silicates. The original chondritic material is characterized by specific elemental ratios, e.g., a high $\mathrm{Mg} / \mathrm{Si}$ ratio $(\sim 1$; Rietmeijer, 1998). Similar values $(\sim 0.85)$ were determined for the small (particle diameter $<500 \mathrm{~nm}$ ) silicate spheres found during ESSenCe and RECONCILE. The larger silicate spheres (particle diameter $>500 \mathrm{~nm}$ ), which were only found in the RECONCILE samples, show lower Mg / Si ratios $(\sim 0.4)$. It is known that high-temperature processing leads to a loss of more volatile materials. Volatility studies have shown that within the residues up to a remaining fraction of $20 \% \mathrm{Mg}$ and $\mathrm{Si}$ acts similar, but for even higher ablation rates $\mathrm{Mg}$ becomes depleted in contrast to $\mathrm{Si}$ (Floss et al., 1996). In this way the residual spheres, as the remains of heated but not fully ablated material, can show completely different elemental ratios. In this way Rietmeijer (2000) states the following: "We may consider the possibility that non-chondritic element abundances are a norm rather than an exception." Twenty percent of the large silicate particles during RECONCILE are not spheres but show irregular morphologies (Fig. 3f). Even when this fact does not allow an unambiguous assignment to a high-temperature history, these particles can originate from cosmic dust. A different source for such particles is discussed by Zolensky et al. (1989). They suggested that such silicates with nonchondritic composition (which were the majority in the size range $1-5 \mu \mathrm{m}$ in their study) may originate from aerospace activities. They listed as sources solid rocket fuel exhaust, solid rocket motor ablation, thermal reflective paint from the outer hull of spacecraft and ablating hardware from satellites and discarded rocket sections in low-Earth orbit.

\subsubsection{C / Si mixed particles}

Detailed analysis of the C/Si-mixed agglomerates shows, that carbon and silicon are often distributed heterogeneously within the analyzed agglomerates (Fig. 3e). At least half of the mixtures were agglomerates of carbon-rich grains and silicate particles. This is a hint for carbonaceous chondrites. In this way, a cosmic origin is the most likely source for the C / Si mixed particles.

\subsubsection{Mixed metal / metal oxides}

As mentioned above, these particles show a composition which is similar to certain anthropogenic metal alloys. In the NASA cosmic dust catalog (Warren et al., 2011), such "alloylike" stratospheric particles are partly classified as cosmic and partly as artificial terrestrial contamination.
As metallic inlet abrasion particles are a well-known artifact of stratospheric particle collection (Murphy et al., 2004) this process cannot be excluded as a possible source for at least some of these particles. This is supported by the fact that the average diameter of this mixed group is $1.65 \mu \mathrm{m}$, the largest one of all observed groups. Furthermore, twothirds (62 of 93) of all observed refractory particles larger than $2 \mu \mathrm{m}$ belong to this group (see also size distribution in Fig. 9). Thus, on the one hand, with regard to the high number of such large particles in such a small sample volume, contamination is not an unlikely source.

On the other hand, there is also a variety of findings supporting the particles' non-artifact origin. First, $75 \%$ of the mixed particles are spheres or contain spheres or other rounded structures, pointing to a high-temperature history. This is a strong hint that the particles do not originate from the inlet or the sampling line of the sampling system, as abrasion particles would not show such spherical structures. Second, these particles were observed neither in all RECONCILE samples nor in blind samples taken before and during RECONCILE. As sampling conditions inside the aircraft were the same for all RECONCILE flights, contamination should thus be expected to be found in all samples similarly.

Thus, we consider these particles in the present work not to be instrumental artifacts of the aircraft sampling.

The size, mixing state and chemical composition of these particles fit to particles described by Mackinnon et al. (1982) in the Johnson Space Center Stratospheric Dust Collection and classified as "Al prime". Of all detected agglomerates in this study, $31 \%$ belong to this group. Mackinnon et al. describe variable abundance of $\mathrm{Al}, \mathrm{Fe}$ and $\mathrm{Si}$ in these supermicron agglomerates, which is in accordance with the complex mixing state of Si-rich, Al-rich and Fe-rich primary particles, which we determined within the complex agglomerates. As the samples during the Johnson Space Center Stratospheric Dust Collection were collected on flat-plate dust collectors mounted on the wings of the aircrafts, it is highly unlikely that the particles in these samples are instrumental artifacts. Mackinnon et al. assume that the source of the majority of the Al prime particles is anthropogenic (partly solid rocket fuel exhaust) and that a minority has an extraterrestrial origin.

A possible origin of these particles might be, similar to the case of the Fe-rich particles, aerospace activities (rocket exhaust, space debris), according to Zolensky et al. (1989). Fe and $\mathrm{Al}$, but also other metals, are among the most abundant elements in such particles which also have a high chance of having undergone high-temperature processes. A space debris source is also indicated by the findings of Weigel et al. (2014). During the RECONCILE campaign they observed a strong subsidence; i.e., most particles will have their origin at high altitudes (e.g., extraterrestrial, MDP). The contribution of meteoric particles is discussed controversially, but recent investigations suggest that meteoric material contributes a significant fraction of the total stratospheric aerosol mass (Carslaw and Kärcher, 2006). 
For example, Jackman et al. (1998), Danilin et al. (2001) and Deshler (2008) have discussed the contribution of space debris and rocket exhaust particles for the abundance of refractory stratospheric particles. While they assume that the abundance of such particles may be on average low, Newman et al. (2001) has found that the exhaust plume of a single rocket could have been observed over relatively large timeand spatial scales. In this way such an individual event (either a rocket plume or a plume of space debris or meteoric material) could lead to an drastically higher abundance of such particles in individual stratospheric particle samples and could be one possible explanation for the large number of observed large refractory particles during the RECONCILE experiment. The Fe- and Al-containing particles are commonly observed in stratospheric aerosol particles. Cziczo et al. (2002) describe Fe and Al signatures in their mass spectrometry measurements; Kordesh et al. (1983), Sheridan et al. (1994) and Chen et al. (1998) also describe particles with high $\mathrm{Fe}$ and $\mathrm{Al}$ contents. In this way, we may hypothesize that their source must be widespread.

In some of the observed mixed metal particles $\mathrm{K}$ and $\mathrm{F}$ were also determined. These elements are often used as fingerprints for welding processes (Berlinger et al., 2011), as potassium fluoride is used as flux melting agent. Thus, at least a fraction of the mixed metal / metal oxide particles will have an anthropogenic (space debris, rockets) and not a cosmic origin.

\subsubsection{Pb-rich particles}

In both field campaigns small $(\sim 50 \mathrm{~nm}) \mathrm{Pb}$-rich particles were observed. Most of the small $\mathrm{Pb}$-rich particles were embedded in volatile material. The $\mathrm{Pb}$-rich inclusions become visible under electron bombardment in the ESEM, when the volatile material is evaporating (Fig. 5). It has to be noted that because of the high average atomic number these particles are extremely bright in SE image in the electron microscope (see Fig. 6a) and thus may be over-represented in the qualitatively analysis of the fine stage. The mass abundance of this component can be very low. Nevertheless, by in situ mass spectrometry measurements Murphy et al. (2007b) found lead in 5 to $25 \%$ of all analyzed particles in the upper troposphere. They discussed aviation fuel and coal combustion as a source for these particles. A distinct internal contamination source for lead could not be discovered, but because of the ubiquitous distribution of trace amounts of lead in the environment (Murphy et al., 2007b) it cannot completely be excluded.

\subsubsection{Soot}

Soot particles were also found in the stratosphere by other researchers (e.g., Renard et al., 2008; Cziczo et al., 2002; Pueschel et al., 1992, 1997; Sheridan et al., 1994; Strawa et al., 1999). As the most probable source aviation fuel, rocket launches and forest fires are discussed. Bigg (2011) also proposed MDPs as a possible source for soot particles in the stratosphere. This would possibly explain the observation that during RECONCILE the abundance of small soot particles and of the larger mixed metal particles (also originating from upper stratosphere/mesosphere) in individual flight samples seem to be partly correlated. A self-match of the Geophysica aircraft can be excluded. During RECONCILE one self-match flight was performed (30 January 2010; see Suminska-Ebersoldt et al., 2012) and it was shown that such a self-match becomes directly visible in the data of diverse Geophysica measuring devices like the COPAS system (Weigel et al., 2009).

\subsubsection{Aluminium oxide spheres}

Solid rocket motors are known to be a source for aluminumrich particles in the stratosphere (e.g., Cziczo et al., 2002). The impact of these particles on the heterogeneous chemistry of stratospheric ozone has been studied since the early 1970s as part of the Climatic Impact Assessment Program (CIAP) (Hoshizaki, 1975). Detailed discussion can be found, for example, in Danilin et al. (2001), Jackman et al. (1998) and Denison et al. (1994). Cofer III et al. (1991) measured a bimodal size distribution of AOSs in the Space Shuttle plume with peaks at 2 and $<0.3 \mu \mathrm{m}$.

Small AOS spheres (diameter around $100 \mathrm{~nm}$ ) were observed during RECONCILE and ESSenCe (see Fig. 7a). While no externally mixed supermicron AOS particles were detected during both campaigns, supermicron AOSs were part of the complex agglomerates within the mixed metal / metal oxide group, observed during RECONCILE and described in Sect. 4.1.5. In Kiruna, rockets are launched within the framework of the ESRANGE program. A local plume from this activity cannot be expected as the last rocket launches from Kiruna prior to RECONCILE were conducted on 22 and 29 November 2009 and therefore around 7 weeks before the sampling flights. However, there is a constant entry of particles from space launch activities in to the stratosphere and mesosphere. For example, during the time period of RECONCILE at least nine space launches took place, including Proton rockets, Soyuz-U, Delta rockets and the Space Shuttle Endeavour (see www.spacelaunchreport.com/ $\log 2010 . \mathrm{html})$.

\subsection{Atmospheric situation during sampling}

Within the samples taken during the one single sampling flight of the ESSenCe campaign, only a small number (106) of sub- $\mu \mathrm{m}$ and no super- $\mu \mathrm{m}$ refractory particles were detected. In contrast some 100 large refractory particles were observed within the 11 RECONCILE flight samples. Further on, for the 11 RECONCILE flights at least two different situations were found. Flights 2, 4 and 5 deliver samples with $\mathrm{Ca}$-rich particles, silicates, carbon / silicate-mixtures and $\mathrm{Fe}$ - 
rich particles, while the samples $1,3,6,8,10,12$ and 13 show an additionally high abundance of mixed metal / metal oxide particles. A detailed discussion of the flight conditions with respect to PSC occurrence and polar vortex situation for all conducted flights can be found in Weigel et al. (2014) and Molleker et al. (2014). The most important data for the different sampling flights are summarized in Fig. 2 and Table 1. According to the classification of Weigel et al. (2014), three sampling flights were performed outside of vortex, five in the central vortex and three under mixed vortex conditions (like vortex walls). An assessment of PSC occurrence during the specific sampling times is based on the data from Molleker et al. (2014). These data suggest a PSC occurrence for the samples 1, 2, 3, 4, 5 of RECONCILE and the single flight A of ESSenCe. It has to be noted, however, that due to the long sampling time and the unknown density and exact location of the PSCs, the real impact of the PSCs on the single samples is difficult to estimate. For example, a sample from this subset might originate from anywhere between a PSC core to the region close to, but not within, a PSC. Thus, it cannot be concluded that the PSC conditions during these six flights were completely comparable nor that all sampled particles from these events originate from a dense PSC.

Nevertheless, it is a clear result that all samples without any mixed metal / metal oxide particles were taken within classified PSC events. An exception is the RECONCILE flight 9, where no mixed metal / metal oxide particles were observed. However, this flight took place in the outer vortex and at (in contrast to the other flights) a high potential temperature of $\sim 500 \mathrm{~K}$ (see Table 1 and Fig. 2), indicating a different air mass origin. Within the PSC samples the highest abundance of Ca-rich particles were also determined.

Further on, there is generally much variation in the potential temperature $(\Theta)$ of the different flights, ranging from $\Theta=400 \mathrm{~K}$ up to values of $\Theta=515 \mathrm{~K}$, indicating potential different air masses as source for the analyzed refractory particles. In general, it is difficult to compare the ESSenCe situation with a young vortex in early winter with the RECONCILE situation with advanced subsidence in late winter.

In all ESSenCe and in three of five RECONCILE samples, which were taken within distinct PSC events, large non-volatile particles were almost completely absent. During ESSenCe inside the PSC no refractory particles larger than $500 \mathrm{~nm}$ could be detected at all and only a small number $(116)$ of small $(<500 \mathrm{~nm})$ refractory particles were determined. Besides around $35 \% \mathrm{Mg}$-rich silicate spheres and $25 \%$ Fe-rich spheres, which have predominantly cosmic origin, $25 \%$ AOSs presumably from rocket launches were also detected and $15 \%$ lead-rich particles from an unknown source.

Weigel et al. (2014) state that during RECONCILE air masses from the upper stratosphere and mesosphere were subsiding inside the Arctic winter vortex, thus initializing a transport of refractory aerosol into the lower stratosphere
$(\Theta<500 \mathrm{~K})$. The strength and extent of this downward transport depend on the dynamical evolution of the vortex.

\section{Conclusion}

1. During the polar stratospheric flight campaign RECONCILE 759 refractory particles with diameters above $500 \mathrm{~nm}$ were detected in 11 flight samples. During this campaign the air mass subsidence inside the Arctic winter vortex from upper stratosphere and mesosphere was advanced, thus enabling transport of these refractory particles into the lower stratosphere $(\Theta<500 \mathrm{~K})$. Fe-rich particles, Ca-rich particles, silicates, silicate / carbon mixed particles and mixed metal particles will most likely originate from different sources, such as meteoric material, space debris and to lower extent terrestrial sources. For an unambiguous identification of distinct particle origin further research is necessary.

2. In the ESSenCe flight samples (single flight within a PSC) no large refractory particles were observed. Most likely, the transport of refractory particles from upper stratosphere and mesosphere into the lower stratosphere did not take place in the early-winter situation (young vortex) present during ESSENCE. The difference in refractory particle abundance between the two campaigns clearly shows the necessity for further investigations of the stratospheric aerosol in the polar region, especially under advanced subsidence conditions.

3. Refractory particles can provide a surface for heterogeneous condensation during PSC events. The occurrence and importance of this possible PSC nucleation pathway has been controversially discussed and tested in laboratory experiments in the last years (e.g., Biermann et al., 1996; Engel et al., 2013).

While the data base is still sparse, we have observed the general tendency that the number of large refractory particles, which were encountered during the special conditions of RECONCILE, decreases during PSC events. We explain this experimental observation by the activation of the large refractory particles into PSC elements under favorable conditions. In this situation sampling of these particles by the fast-flying Geophysica aircraft is prevented due to particle and subsequent inertia growth.

\section{Data availability}

The data set is available for the community and can be accessed by request to Martin Ebert (mebert@geo.tudarmstadt.de) of the Technical University Darmstadt. 
Acknowledgements. This work was partly supported by the project ROMIC-SPITFIRE sponsored by the Federal Ministry of Education and Research (FKZ 01LG1205D) and partly by STRATOCLIM sponsored by the European Union Seventh Framework Programme (FP7), project reference 603557. The authors thank the M-55 Geophysica team and the MDB (Myasishev Design Bureau, Moscow, Russia) for planning and carrying out the flights and Enviscope $\mathrm{GmbH}$ for logistical support during the RECONCILE campaign. The RECONCILE campaign was funded by FP7 under the grant number RECONCILE-226365-FP7-ENV-2008-1. ESSenCe was partly supported by the German Research Foundation (DFG) under contract HALO-SPP 1294/GR 3786. Our research received funding from the European Research Council under FP7 (FP/20072013)/ERC grant agreement no. 321040 (EXCATRO).

Edited by: F. Khosrawi

Reviewed by: two anonymous referees

\section{References}

Amyx, K., Sternovsky, Z., Knappmiller, S., Robertson, S., Horanyi, M., and Gumbel, J.: In-situ measurement of smoke particles in the wintertime polar mesosphere between 80 and $85 \mathrm{~km}$ altitude, J. Atmos. Sol.-Terr. Phy., 70, 61-70, doi:10.1016/j.jastp.2007.09.013, 2008.

Bardeen, C. G., Toon, O. B., Jensen, E. J., Marsh, D. R., and Harvey, V. L.: Numerical simulations of the threedimensional distribution of meteoric dust in the mesosphere and upper stratosphere, J. Geophys. Res.-Atmos., 113, D17202, doi:10.1029/2007jd009515, 2008.

Berlinger, B., Benker, N., Weinbruch, S., Vov, B. L., Ebert, M., Koch, W., Ellingsen, D. G., and Thomassen, Y.: Physicochemical characterisation of different welding aerosols, Anal. Bioanal. Chem., 399, 1773-1780, doi:10.1007/s00216-010-4185-7, 2011.

Biermann, U. M., Presper, T., Koop, T., Mossinger, J., Crutzen, P. J., and Peter, T.: The unsuitability of meteoritic and other nuclei for polar stratospheric cloud freezing, Geophys. Res. Lett., 23, 1693-1696, 1996.

Bigg, E. K.: Sources of particulates in the upper stratosphere, J. Cosmol., 16, 6677-6687, 2011.

Bigg, E. K.: Sources of insoluble inclusions in stratospheric sulfate particles, Meteorit. Planet. Sci., 47, 799-805, doi:10.1111/j.1945-5100.2012.01346.x, 2012.

Bigg, E. K., Ono, A., and Thompson, W. J.: Aerosols at altitudes between 20 and $37 \mathrm{~km}$, Tellus, 22, 550-563, doi:10.1111/j.21533490.1970.tb00522.x, 1970.

Bigg, E. K., Kviz, Z., and Thompson, W. J.: Electron microscope photographs of extraterrestrial particles, Tellus, 23, 247-260, doi:10.1111/j.2153-3490.1971.tb00567.x, 1971.

Borrmann, S., Kunkel, D., Weigel, R., Minikin, A., Deshler, T., Wilson, J. C., Curtius, J., Volk, C. M., Homan, C. D., Ulanovsky, A., Ravegnani, F., Viciani, S., Shur, G. N., Belyaev, G. V., Law, K. S., and Cairo, F.: Aerosols in the tropical and subtropical UT/LS: insitu measurements of submicron particle abundance and volatility, Atmos. Chem. Phys., 10, 5573-5592, doi:10.5194/acp-105573-2010, 2010.

Campbell, P. and Deshler, T.: Condensation nuclei measurements in the midlatitude (1982-2012) and Antarctic (1986-2010) strato- sphere between 20 and $35 \mathrm{~km}$, J. Geophys. Res.-Atmos., 119, 137-152, doi:10.1002/2013jd019710, 2014.

Carslaw, K. C. and Kärcher, B.: Stratospheric aerosol processes, in: Assessment of Stratospheric Aerosol Properties, edited by: Thomason, L. and Peter, T., WCRP 124, WMO/TD 1295, SPARC Rep. 4, World Meteorol. Organ., Geneva, Switzerland, 2006.

Chang, H.-Y. A., Koop, T., Molina, L. T., and Molina, M. J.: Phase Transitions in Emulsified $\mathrm{HNO}_{3} / \mathrm{H}_{2} \mathrm{O}$ and $\mathrm{HNO}_{3} / \mathrm{H}_{2} \mathrm{SO}_{4} / \mathrm{H}_{2} \mathrm{O}$ Solutions, J. Phys. Chem. A, 103, 26732679, doi:10.1021/jp9841034, 1999.

Chen, Y., Kreidenweis, S. M., McInnes, L. M., Rogers, D. C., and DeMott, P. J.: Single particle analyses of ice nucleating aerosols in the upper troposphere and lower stratosphere, Geophys. Res. Lett., 25, 1391-1394, 1998.

Choël, M., Deboudt, K., Osán, J., Flament, P., and Van Grieken, R.: Quantitative Determination of Low-Z Elements in Single Atmospheric Particles on Boron Substrates by Automated Scanning Electron Microscopy-Energy-Dispersive X-ray Spectrometry, Anal. Chem., 77, 5686-5692, doi:10.1021/ac050739x, 2005.

Cofer III, W. R., Purgold, G. C., Winstead, E. L., and Edahl, R. A.: Space Shuttle Exhausted Aluminum Oxide: A measured particle size distribution, J. Geophys. Res.-Atmos., 96, 17371-17376, 1991.

Curtius, J., Weigel, R., Vössing, H.-J., Wernli, H., Werner, A., Volk, C.-M., Konopka, P., Krebsbach, M., Schiller, C., Roiger, A., Schlager, H., Dreiling, V., and Borrmann, S.: Observations of meteoric material and implications for aerosol nucleation in the winter Arctic lower stratosphere derived from in situ particle measurements, Atmos. Chem. Phys., 5, 3053-3069, doi:10.5194/acp-5-3053-2005, 2005.

Cziczo, D. J., Thomson, D. S., and Murphy, D. M.: Ablation, flux, and atmospheric implications of meteors inferred from stratospheric aerosol, Science, 291, 1772-1775, 2001.

Cziczo, D. J., Murphy, D. M., Thomson, D. S., and Ross, M. N.: Composition of individual particles in the wakes of an Athena II rocket and the space shuttle, Geophys. Res. Lett., 29, 2037, doi:10.1029/2002GL015991, 2002.

Danilin, M. Y., Ko, M. K. W., and Weisenstein, D. K.: Global implications of ozone loss in a space shuttle wake, J. Geophys. Res.Atmos., 106, 3591-3601, 2001.

Della Corte, V., Rietmeijer, F. J. M., Rotundi, A., Ferrari, M., and Palumbo, P.: Meteoric $\mathrm{CaO}$ and carbon smoke particles collected in the upper stratosphere from an unanticipated source, Tellus B, 65, 20174, doi:10.3402/tellusb.v65i0.20174, 2013.

Deshler, T.: A review of global stratospheric aerosol: Measurements, importance, life cycle, and local stratospheric aerosol, Atmos. Res., 90, 223-232, 2008.

Deshler, T., Larsen, N., Weissner, C., Schreiner, J., Mauersberger, K., Cairo, F., and Blum, U.: Large nitric acid particles at the top of an Arctic stratospheric cloud, J. Geophys. Res.-Atmos., 108, 4517, doi:10.1029/2003JD003479, 2003.

Denison, M., Lamb, J. J., Bjorndahl, W. D., Wong, E. Y., and Lohn, P. D.: Solid rocket exhaust in the stratosphere-Plume diffusion and chemical reactions, J. Spacecraft Rockets, 31, 435-442, 1994.

Dhomse, S. S., Saunders, R. W., Tian, W., Chipperfield, M. P., and Plane, J. M. C.: Plutonium-238 observations as a test of modeled transport and surface deposition of meteoric smoke particles, 
Geophys. Res. Lett., 40, 4454-4458, doi:10.1002/grl.50840, 2013.

Engel, I., Luo, B. P., Pitts, M. C., Poole, L. R., Hoyle, C. R., Grooß, J.-U., Dörnbrack, A., and Peter, T.: Heterogeneous formation of polar stratospheric clouds - Part 2: Nucleation of ice on synoptic scales, Atmos. Chem. Phys., 13, 10769-10785, doi:10.5194/acp13-10769-2013, 2013.

Floss, C., El Goresy, A., Zinner, E., Kransel, G., Rammensee, W., and Palme, H.: Elemental and isotopic fractionations produced through evaporation of the Allende CV chondrilte: Implications for the origin of HAL-type hibonite inclusions, Geochim. Cosmochim. Ac., 60, 1975-1997, 1996.

Frankland, V. L., James, A. D., Feng, W., and Plane, J. M. C.: The uptake of $\mathrm{HNO}_{3}$ on meteoric smoke analogues, J. Atmos. Sol.Terr. Phy., doi:10.1016/j.jastp.2015.01.010, 2015.

Friedrich, M., Rapp, M., Blix, T., Hoppe, U. P., Torkar, K., Robertson, S., Dickson, S., and Lynch, K.: Electron loss and meteoric dust in the mesosphere, Ann. Geophys., 30, 1495-1501, doi:10.5194/angeo-30-1495-2012, 2012.

Fromm, M. D., Alfred, J., Hornstein, J., Bevilacqua, R., Shettle, E., Servranckx, R. Zhanqing, L., and Brian, S.: Observations of boreal forest fire smoke in the stratosphere by POAM III, SAGE II, and lidar in 1998, Geophys. Res. Lett., 27, 1407-1410, 2000.

Gettelman, A., Hoor, P., Pan, L. L., Randel, W. J., Hegglin, M. I., and Birner, T.: The extratropical upper troposphere and lower stratosphere, Rev. Geophys., 49, RG3003, doi:10.1029/2011rg000355, 2011.

Hermann, M., Stratmann, F., Wilck, M., and Wiedensohler, A.: Sampling Characteristics of an Aircraft-Borne Aerosol Inlet System, J. Atmos. Ocean. Tech., 18, 7-19, doi:10.1175/15200426(2001)018<0007:scoaab>2.0.co;2, 2001.

Hervig, M. E., Gordley, L. L., Deaver, L. E., Siskind, D. E., Stevens, M. H., Russell, J. M., Bailey, S. M., Megner, L., and Bardeen, C. G.: First Satellite Observations of Meteoric Smoke in the Middle Atmosphere, Geophys. Res. Lett., 36, L18805, doi:10.1029/2009g1039737, 2009.

Hoshizaki, H., Anderson, L. B., Conti, R. J., Farlow, N., Meyer, J. W., Overcamp, T., Redler, K. O., and Watson, V.: Aircraft wake microscale phenomena, CIAP Monograph, 3, 60-73, 1975.

Hua, X. and Buseck, P. R.: Unusual forms of magnetite in the Orgueil carbonaceous chondrite, Meteorit. Planet. Sci., 33, A215-A220, 1998.

Jackman, C. H., Considine, D. B., and Fleming, E. L.: A global modeling study of solid rocket aluminum oxide emission effects on stratospheric ozone, Geophys. Res. Lett., 25, 907-910, 1998.

Jost, H. J., Drdla, K., Stohl, A., Pfister, L., Loewenstein, M., Lopez, J. P., and Bui, T. P.: In-situ observations of mid-latitude forest fire plumes deep in the stratosphere, Geophys. Res. Lett., 31, L11101, doi:10.1029/2003GL019253, 2004.

Junge, C. E.: Air Chemistry, Academic, New York, 1963.

Kandler, K., Benker, N., Bundke, U., Cuevas, E., Ebert, M., Knippertz, P., Rodríguez, S., Schütz, L., and Weinbruch, S.: Chemical composition and complex refractive index of Saharan Mineral Dust at Izaña, Tenerife (Spain) derived by electron microscopy, Atmos. Environ., 41, 8058-8074, doi:10.1016/j.atmosenv.2007.06.047, 2007.

Kaufmann, M., Blank, J., Guggenmoser, T., Ungermann, J., Engel, A., Ern, M., Friedl-Vallon, F., Gerber, D., Grooß, J. U., Guenther, G., Höpfner, M., Kleinert, A., Kretschmer, E., Latzko,
Th., Maucher, G., Neubert, T., Nordmeyer, H., Oelhaf, H., Olschewski, F., Orphal, J., Preusse, P., Schlager, H., Schneider, H., Schuettemeyer, D., Stroh, F., Suminska-Ebersoldt, O., Vogel, B., M. Volk, C., Woiwode, W., and Riese, M.: Retrieval of threedimensional small-scale structures in upper-tropospheric/lowerstratospheric composition as measured by GLORIA, Atmos. Meas. Tech., 8, 81-95, doi:10.5194/amt-8-81-2015, 2015.

Kordesh, K. M., Mackinnon, I. D. R., and McKay, D. S.: A new classification and database for stratospheric dust particles, in: Lunar and Planetary Science Conference, Lunar and Planetary Institute, Houston, TX, 389-390, 1983.

Mackinnon, I. D. R., Mckay, D. S., Nace, G., and Isaacs, A. M.: Classification of the Johnson Space Center Stratospheric Dust Collection, J. Geophys. Res., 87, A413-A421, 1982.

Mattis, I., Siefert, P., Muller, D., Tesche, M., Hiebsch, A., Kanitz, T., Schmidt, J., Finger, F., Wandinger, U., and Ansmann, A.: Volcanic aerosol layers observed with multiwavelength Raman lidar over central Europe in 2008-2009, J. Geophys. Res.-Atmos., 115, D00104, doi:10.1029/2009jd013472, 2010.

Megner, L., Siskind, D. E., Rapp, M., and Gumbel, J.: Global and temporal distribution of meteoric smoke: A two-dimensional simulation study, J. Geophys. Res.-Atmos., 113, D03202, doi:10.1029/2007jd009054, 2008.

Molleker, S., Borrmann, S., Schlager, H., Luo, B., Frey, W., Klingebiel, M., Weigel, R., Ebert, M., Mitev, V., Matthey, R., Woiwode, W., Oelhaf, H., Dörnbrack, A., Stratmann, G., Grooß, J.U., Günther, G., Vogel, B., Müller, R., Krämer, M., Meyer, J., and Cairo, F.: Microphysical properties of synoptic-scale polar stratospheric clouds: in situ measurements of unexpectedly large $\mathrm{HNO}_{3}$-containing particles in the Arctic vortex, Atmos. Chem. Phys., 14, 10785-10801, doi:10.5194/acp-14-10785-2014, 2014.

Mossop, S. C.: Stratospheric particles at $20 \mathrm{~km}$ altitude, Geochim. Cosmochim. Ac., 29, 201-207, 1965.

Murphy, D. M., Thomson, D. S., and Mahoney, M. J.: In Situ Measurements of Organics, Meteoritic Material, Mercury, and Other Elements in Aerosols at 5 to 19 Kilometers, Science, 282, 1664 1669, doi:10.1126/science.282.5394.1664, 1998.

Murphy, D. M., Cziczo, D. J., Hudson, P. K., Thomson, D. S., Wilson, J. C., Kojima, T., and Buseck, P. R.: Particle generation and resuspension in aircraft inlets when flying in clouds, Aerosol Sci. Technol., 38, 401-409, 2004.

Murphy, D. M., Cziczo, D. J., Hudson, P. K., and Thomson, D. S.: Carbonaceous material in aerosol particles in the lower stratosphere and tropopause region, J. Geophys. Res.-Atmos., 112, D04203, doi:10.1029/2006JD007297, 2007a.

Murphy, D. M., Hudson, P. K., Cziczo, D. J., Gallavardin, S., Froyd, K. D., Johnston, M. V., Middlebrook, A. M., Reinard, M. S., Thomson, D. S., Thornberry, T., and Wexler, A. S.: Distribution of lead in single atmospheric particles, Atmos. Chem. Phys., 7, 3195-3210, doi:10.5194/acp-7-3195-2007, 2007b.

Murphy, D. M., Froyd, K. D., Schwarz, J. P., and Wilson, J. C.: Observations of the chemical composition of stratospheric aerosol particles, Q. J. Roy. Meteor. Soc., 140, 1269-1278, doi:10.1002/qj.2213, 2013.

Newman, P. A., Wilson, J. C., Ross, M. N., Brock, C. A., Sheridan, P. J., Schoeberl, M. R., Lait, L. R., Bui, T. P., Loewenstein, M., and Podolske, J. R.: Chance encounter with a stratospheric kerosene rocket plume from Russia over California, Geophys. Res. Lett., 28, 959-962, 2001. 
Plane, J. M. C.: Cosmic dust in the earth's atmosphere, Chem. Soc. Rev., 41, 6507-6518, 2012.

Plane, J. M. C., Saunders, R. W., Hedin, J., Stegman, J., Khaplanov, M., Gumbel, J., Lynch, K. A., Bracikowski, P. J., Gelinas, L. J., Friedrich, M., Blindheim, S., Gausa, M., and Williams, B. P.: A combined rocket-borne and ground-based study of the sodium layer and charged dust in the upper mesosphere, J. Atmos. SolarTerr. Phy., 118, 151-160, 2014.

Pueschel, R. F., Blake, D. F., Snetsinger, K. G., Hansen, A. D. A., Verma, S., and Kato, K.: Black carbon (soot) aerosol in the lower stratosphere and upper troposphere, Geophys. Res. Lett., 19, 1659-1662, 1992.

Pueschel, R. F., Boering, K. A., Verma, S., Howard, D., Ferry, G. V., Goodman, J., Allen, D. A., and Hamill, P.: Soot aerosol in the lower stratosphere: Pole-to-pole variability and contribution by aircrafts, J. Geophys. Res.-Atmos., 102, 13113-13118, 1997.

Raabe, O. G., Braaten, D. A., Axelbaum, R. L., Teague, S. V., and Cahill, T. A.: Calibration studies of the DRUM impactor, J. Aerosol Sci., 19, 183-195, 1988.

Rapp, M. and Strelnikova, I.: Measurements of meteor smoke particles during the ECOMA-2006 campaign: 1. Particle detection by active photoionization, J. Atmos. Sol.-Terr. Phy., 71, 477-485, 2009.

Rapp, M., Strelnikova, I., and Gumbel, J.: Meteoric smoke particles: Evidence from rocket and radar techniques, Adv. Space Res., 40, 809-817, 2007.

Rapp, M., Plane, J. M. C., Strelnikov, B., Stober, G., Ernst, S., Hedin, J., Friedrich, M., and Hoppe, U.-P.: In situ observations of meteor smoke particles (MSP) during the Geminids 2010: constraints on MSP size, work function and composition, Ann. Geophys., 30, 1661-1673, doi:10.5194/angeo-30-1661-2012, 2012.

Renard, J.-B., Brogniez, C., Berthet, G., Bourgeois, Q., Gaubicher, B., Chartier, M., Balois, J.-Y., Verwaerde, C., Auriol, F., Francois, P., Daugeron, D., and Engrand, C.: Vertical distribution of the different types of aerosols in the stratosphere, Detection of solid particles and analysis of their spatial variability, J. Geophys. Res., 113, D21303, doi:10.1029/2008JD010150, 2008.

Rietmeijer, F. J. M.: Chapter 2 - Interplanetary dust particles in Reviews in Mineralogy, Vol. 36 Planetary Materials, The Mineralogical Society of America, Washington DC, USA, 1998.

Rietmeijer, F. J.: Interrelationships among meteoric metals, meteors, interplanetary dust, micrometeorites, and meteorites, Meteorit. Planet. Sci., 35, 1025-1041, 2000.

Saunders, R. W., Möhler, O., Schnaiter, M., Benz, S., Wagner, R., Saathoff, H., Connolly, P. J., Burgess, R., Murray, B. J., Gallagher, M., Wills, R., and Plane, J. M. C.: An aerosol chamber investigation of the heterogeneous ice nucleating potential of refractory nanoparticles, Atmos. Chem. Phys., 10, 1227-1247, doi:10.5194/acp-10-1227-2010, 2010.

Saunders, R. W., Dhomse, S., Tian, W. S., Chipperfield, M. P., and Plane, J. M. C.: Interactions of meteoric smoke particles with sulphuric acid in the Earth's stratosphere, Atmos. Chem. Phys., 12, 4387-4398, doi:10.5194/acp-12-4387-2012, 2012.

Sheridan, P. J., Brock, C. A., and Wilson, J. C.: Aerosol particles in the upper troposphere and lower stratosphere: Elemental composition and morphology of individual particles in northern midlatitudes, Geophys. Res. Lett., 21, 2587-2590, 1994.
Stefanutti, L., Sokolov, L., MacKenzie, A. R., Balestri, S., and Khattatov, V.: The M-55 Geophysica as a platform for the Airborne Polar Experiment, J. Atmos. Ocean. Tech., 16, 1303-1312, 1999.

Strawa, A. W., Drdla, K., Ferry, G. V., Verma, S., Pueschel, R. F., Yasuda, M., and Cohen, R.: Carbonaceous aerosol (soot) measured in the lower stratosphere during POLARIS and its role in stratospheric photochemistry, J. Geophys. Res., 104, 753-766, 1999.

Suminska-Ebersoldt, O., Lehmann, R., Wegner, T., Grooß, J.-U., Hösen, E., Weigel, R., Frey, W., Griessbach, S., Mitev, V., Emde, C., Volk, C. M., Borrmann, S., Rex, M., Stroh, F., and von Hobe, $\mathrm{M}$.: $\mathrm{ClOOCl}$ photolysis at high solar zenith angles: analysis of the RECONCILE self-match flight, Atmos. Chem. Phys., 12, 13531365, doi:10.5194/acp-12-1353-2012, 2012.

Targino, A. C., Krejci, R., Noone, K. J., and Glantz, P.: Single particle analysis of ice crystal residuals observed in orographic wave clouds over Scandinavia during INTACC experiment, Atmos. Chem. Phys., 6, 1977-1990, doi:10.5194/acp-6-1977-2006, 2006.

Vernier, J. P., Thomason, L. W., Pommereau, J. P., Bourassa, A., Pelon, J., Garnier, A., Hauchecorne, A., Blanot, L., Trepte, C., Degenstein, D., and Vargas, F.: Major influence of tropical volcanic eruptions on the stratospheric aerosol layer during the last decade, Geophys. Res. Lett., 38, L12807, doi:10.1029/2011g1047563, 2011.

von Hobe, M., Bekki, S., Borrmann, S., Cairo, F., D’Amato, F., Di Donfrancesco, G., Dörnbrack, A., Ebersoldt, A., Ebert, M., Emde, C., Engel, I., Ern, M., Frey, W., Genco, S., Griessbach, S., Grooß, J.-U., Gulde, T., Günther, G., Hösen, E., Hoffmann, L., Homonnai, V., Hoyle, C. R., Isaksen, I. S. A., Jackson, D. R., Jánosi, I. M., Jones, R. L., Kandler, K., Kalicinsky, C., Keil, A., Khaykin, S. M., Khosrawi, F., Kivi, R., Kuttippurath, J., Laube, J. C., Lefèvre, F., Lehmann, R., Ludmann, S., Luo, B. P., Marchand, M., Meyer, J., Mitev, V., Molleker, S., Müller, R., Oelhaf, H., Olschewski, F., Orsolini, Y., Peter, T., Pfeilsticker, K., Piesch, C., Pitts, M. C., Poole, L. R., Pope, F. D., Ravegnani, F., Rex, M., Riese, M., Röckmann, T., Rognerud, B., Roiger, A., Rolf, C., Santee, M. L., Scheibe, M., Schiller, C., Schlager, H., Siciliani de Cumis, M., Sitnikov, N., Søvde, O. A., Spang, R., Spelten, N., Stordal, F., Suminska-Ebersoldt, O., Ulanovski, A., Ungermann, J., Viciani, S., Volk, C. M., vom Scheidt, M., von der Gathen, P., Walker, K., Wegner, T., Weigel, R., Weinbruch, S., Wetzel, G., Wienhold, F. G., Wohltmann, I., Woiwode, W., Young, I. A. K., Yushkov, V., Zobrist, B., and Stroh, F.: Reconciliation of essential process parameters for an enhanced predictability of Arctic stratospheric ozone loss and its climate interactions (RECONCILE): activities and results, Atmos. Chem. Phys., 13, 92339268, doi:10.5194/acp-13-9233-2013, 2013.

Warren, J. L., Achilles, C. N., Todd, N. S., Bastien, R. K., and Zolensky, M. E.: Cosmic Dust Catalog Volume 18 Particles from Collectors L2071, L2076, L2079, L2083, and W7068, NASA Johnson Space Center, Houston, TX 77058, 2011.

Weigel, R., Hermann, M., Curtius, J., Voigt, C., Walter, S., Böttger, T., Lepukhov, B., Belyaev, G., and Borrmann, S.: Experimental characterization of the COndensation PArticle counting System for high altitude aircraft-borne application, Atmos. Meas. Tech., 2, 243-258, doi:10.5194/amt-2-243-2009, 2009.

Weigel, R., Volk, C. M., Kandler, K., Hösen, E., Günther, G., Vogel, B., Grooß, J.-U., Khaykin, S., Belyaev, G. V., and Borrmann, S.: 
Enhancements of the refractory submicron aerosol fraction in the Arctic polar vortex: feature or exception?, Atmos. Chem. Phys., 14, 12319-12342, doi:10.5194/acp-14-12319-2014, 2014.

Wilson, J. C., Lee, S.-H., Reeves, J. M., Brock, C. A., Jonsson, H. H., Lafleur, B. G., Loewenstein, M., Podolske, J., Atlas, E., Boering, K., Toon, G., Fahey, D., Bui, T. P., Diskin, G., and Moore, F.: Steady-state aerosol distributions in the extra-tropical, lower stratosphere and the processes that maintain them, Atmos. Chem. Phys., 8, 6617-6626, doi:10.5194/acp-8-6617-2008, 2008.

Wise, M. E., Brooks, S. D., Garland, R. M., Cziczo, D. J., Martin, S. T., and Tolbert, M. A.: Solubility and freezing effects of $\mathrm{Fe}^{2+}$ and $\mathrm{Mg}^{2+}$ in $\mathrm{H}_{2} \mathrm{SO}_{4}$ solutions representative of upper tropospheric and lower stratospheric sulfate particles, J. Geophys. Res., 108, 4434, doi:10.1029/2003jd003420, 2003.
Xu, L., Okada, K., Iwasaka, Y., Hara, K., Okuhara, Y., Tsutsumi, Y., and Shi, G.: The composition of individual aerosol particle in the troposphere and stratosphere over Xianghe $\left(39.453^{\circ} \mathrm{N}\right.$, 117.03 E), China, Atmos. Environ., 35, 3145-3153, 2001.

Zolensky, M. E., McKay, D. S., and Kaczor, L. A.: A tenfold increase in the abundance of large solid particles in the stratosphere, as measured over the period 1976-1984, J. Geophys. Res.-Atmos., 94, 1047-1056, 1989. 